\title{
PENGARUH WADAH SEMAI BERBAHAN DASAR ORGANIK DAN FUNGI MIKORIZA ARBUSKULA (FMA) TERHADAP PERTUMBUHAN SEMAI BALSA (Ochroma bicolor Rowlee)
}

\author{
The Effects of Organic Pot and Arbuscular Mycorrhizal Fungi (AMF) to wards growth of Ochroma \\ bicolor Rowlee
}

Sri Wilarso Budi ${ }^{1 *}$ dan Rahmawati ${ }^{2}$

(Diterima Juli 2019/Disetujui Oktober 2020)

\begin{abstract}
Balsa (Ochroma bicolor Rowlee) are generally sown using a polybag. Polybag made from plastic that is not easily destroyed or degraded so that it can cause problems for the environment. As an alternative, polybag can be replaced by using organic pot. This research aims to analyze the effect of the treatment of raw materials of organic pot and inoculation Arbuscular Mycorrhizal Fungi (AMF) towards growth of balsa (O. bicolor). This study used Completely Randomized Design (CRD) with two factors. The results showed that treatment of organic pot composition and interaction of addition of AMF has significant effect of height of balsa. A single treatment of organic pot composition has significant effect of total dry weight and diameter increment of balsa. A single treatment by adding AMF has significant effectfor increment of diameter, total dry weight, and percentage of mycorrhiza colonizationat the root ofbalsa.
\end{abstract}

Keyword: Arbuscular Mycorrhizal Fungi (AMF), Balsa (O. bicolor), organic pot

\section{PENDAHULUAN}

Indonesia memiliki sumberdaya hutan yang lu as, namun dari tahun ke tahun kondisi hutan di Indonesia semakin rusak, sementara usaha untuk melakukan reboisasi belum sebanding dengan luasan hutan yang sudah dimanfaatkan. Hal ini mendorong pemerintah untuk membuat kebijakan dalam pengelolaan hutan secara lestari. Salah satu kebijakan pemerintah dalam mengelola hutan lestari ialah melalui pembangunan Hutan Tanaman Industri (HTI) yang lebih produktif, dengan pengelolaan secara intensif dalam menggantikan peran hutan alam sebagai pemasok bahan baku kayu untuk keperluan organik, perabotan, perumahan, dan energi. Salah satu jenis yang dipilih untuk di tanam di areal HTI adalah Balsa (O. bicolor Rowlee). Pengadaan bibit balsa di persemaian, dengan menggunakan polybag sebagai wadah semai sudah umum dilakukan. Setelah penanaman, polybag akan dibuang dan menjadi sampah. Hal ini merupakan kegiatan yang tidak ramah lingkungan dan dapat menimbulkan masalah bagi lingkungan. Polybag adalah salah satu alat yang digunakan sebagai wadah media semai yang kurang ramah lingkungan. Polybag memiliki beberapa keunggulan diantaranya yaitu harga yang relative lebih murah, mudah dalam perawatan, dan pemeliharaan tanaman lebih terkontrol

\footnotetext{
${ }^{1}$ Dosen Departemen Silvikultur, Fakultas Kehutanan Institut Pertanian Bogor

* Penulis korespondensi:

e-mail:wilarso62@yahoo.com

${ }^{2}$ Mahasiswa Departemen Silvikultur, Fakultas

Kehutanan Institut Pertanian Bogor
}

(Budi et al. 2012). Selain itu polybag memiliki beberapa kekurangan yaitu polybag berbahan dasar organik yang bersifat tidak mudah hancur atau terdegradasi sehingga dapat menimbulkan masalah bagi lingkungan. Sebagai alternatif dalam mengatasi masalah tersebut, polybag dapat diganti dengan penggunaan wadah semai berbahan dasar organik yang ramah lingkungan (pot organik).

Pot organik terbuat dari kertas koran bekas yang dicampur dengan kompos atau campuran lainnya yang dapat membantu meningkatkan pertumbuhan tanaman. Salah satu cara untuk meningkatkan pertumbuhan tanaman yaitu dengan adanya mikoriza. Fungi mikoriza merupakan kelompok fungi yang bersimbiosis secara organik atau saling menguntungkan. Menurut Setiadi (1992), mikoriza mampu memperbaiki nutrisi tanaman, meningkatkan pertumbuhan, mempertahankan keanekaragaman tumbuhan, mengingkatkan daya tahan tanaman terhadap serangan organik, dan membantu pertumbuhan tanamanpada kondisi tercemar logam berat. Pengaplikasian fungi mikoriza pada wadah berbahan dasar organik sebelumnya belum pernah dilakukan, sehingga perlu adanya penelitian mengenai pengaruh wadah berbahan dasar organik dan Fungi Mikoriza Arbuskula (FMA) terhadap pertumbuhan semai Balsa (O. bicolor) untuk mengetahui pengaruh adanya inokulasi FMA dalam pot organik terhadap pertumbuhan semai Balsa. Penelitian ini bertujuan untuk menganalisis pengaruh perlakuan bahan baku pot organik dan adanya inokulasi Fungi Mikoriza Arbuskula (FMA) terhadap pertumbuhan semai balsa (O. bicolor Rowlee). 


\section{METODE PENELITIAN}

\section{Waktu dan Tempat Penelitian}

Penelitian ini dilakukan selama 12 bulan dari bulan Mei 2015 sampai dengan Mei 2016. Penelitian ini dilaksanakan di Persemaian Permanen Dramaga IPB. Penghitungan kolonisasi FMA dilakukan di Laboratorium Teknologi Mikoriza dan Peningkatan Kualitas Bibit Departemen Silvikultur Fakultas Kehutanan IPB. Analisis tanah dilakukan di Laboratorium Analisis Tanah Departemen Manajemen Sumberdaya Lahan Fakultas Pertanian IPB.

\section{Alat dan Bahan}

Alat yang digunakan dalam penelitian yaitu alat pencetak pot organik, rak policup, ayakan pasir dan tanah, drum, kompor, wajan, alat penyiram, penggaris, caliper, neraca digital, oven, kamera digital, tallysheet, alat tulis kantor, dan seperangkat komputer.

Bahan yang digunakan dalam penelitian yaitu semai balsa (O. bicolorRowlee), koran bekas, kompos, arang tempurung kelapa, inokulum mikoriza, dan topsoil.

\section{Prosedur Penelitian}

Penelitian ini dilaksanakan dengan tahapan-tahapan sebagai berikut:

\section{Persiapan Pot Organik}

Kertas koran dipotong menjadi ukuran lebih kecil kemudian direndam dalam drum besar berisi air selama 14 hari. Selama perendaman dilakukan pengadukan dan pergantian air. Setelah kertas koran menjadi bubur kemudian diambil untuk dilakukan penyaringan yang berguna untuk mengurangi kadar air.

Pencampuran antara bubur kertas dengan bahan pencampur lain dengan perbandingan sebagai berikut: 1.) bubur kertas koran 100\% (kontrol), 2.) kertas koran + kompos perbandingan $1: 1,3$.) bubur kertas koran + arang tempurung kelapa perbandingan 1:2, dan 4.) bubur kertas koran + kompos + arang tempurung kelapa perbandingan $1: 1: 1$.

Pencetakan dilakukan secara manual dengan menggunakan alat pencetakan pot organik. Pot yang telah dicetak, diletakkan di atas nampan dengan posisi terbalik dan pot dikeringkan dibawah sinar matahari selama 4 hari.

\section{Perkecambahan Balsa (O. bicolor Rowlee)}

Benih balsa dikecambahkan pada media tanah dan pasir dengan perbandingan 1:1 di bak untuk perkecambahan benih dan kemudian di siram setiap pagi dan sore hari.

\section{Pemilihan Semai Balsa (O. bicolor Rowlee)}

Semai yang dipilih yaitu semai balsa yang telah berumur 2 minggu dengan rata-rata tinggi $2 \mathrm{~cm}$.

\section{Persiapan Media Sapih}

Media sapih yaitu topsoil yang berasal dari Persemaian Permanen Dramaga IPB. Topsoil disangrai selama 1 jam terlebih dahulu agar steril.

\section{Penyapihan Semai}

Penyapihandilakukanpadasorehariuntukmengurangip enguapan.

\section{InokulasiTanaman}

Inokulum FMA berupa zeolith yang berisi koloni FMA jenis Gigaspora sp. yang disiapkan dengan dosis $18 \mathrm{~g}$ ( \pm setara dengan 50 spora). Inokulasi dilakukan pada saat penyapihan dengan meletakkan inokulum FMA pada lubang tanam.

\section{Pemeliharaan}

Pemeliharaan semai yang telah disapih dilakukan dengan penyiraman 2 kali sehari yaitu setiap pagi dan sore hari dan pembersihan gulma yang tumbuh pada media tanam.

\section{Pengamatan dan Pengambilan Data}

Parameter yang diukur sebelum pemanenan semai yaitu diameter dan tinggi semai balsa. Pengamatan terhadap diameter dan tinggi dilakukan selama 18 minggu.

\section{Pemanenan dan Pengambilan Data}

Pemanenan dilakukan dengan menghancurkan pot organik kemudian memisahkan tanaman dengan media. Parameter yang diukur setelah pemanenan yaitu kandungan unsur hara pot organik dan media tanam $(\mathrm{N}$, C, Ptotal, dan Ptersedia), berat kering total, Nisbah Pucuk Akar (NPA), dan \% kolonisasi FMA.

\section{Rancangan Percobaan dan Analisis Data}

Rancangan percobaan yang digunakan yaitu Rancangan Acak Lengkap (RAL) dengan dua faktor. Faktor A merupakan komposisi pot organik dan faktor B merupakan penambahan FMA. Faktor A terdiri dari empat perlakuan yaitu perlakuan koran $100 \%$ (A1), perlakuan kombinasi koran dan kompos (A2), perlakuan kombinasi koran dan arang tempurung kelapa (A3), dan perlakuan kombinasi koran, kompos, dan arang tempurung kelapa (A4) dan faktor B terdiri dari dua perlakuan yaitu tanpa penambahan FMA (B1), dan dengan penambahan FMA (B2). Pada faktor A dikombinasikan dengan perlakuan dari faktor B menjadi $\mathrm{AB}$, sehingga terdapat kombinasi yaitu A1B1, A1B2, A2B1, A2B2, A3B1, A3B2, A4B1, dan A4B2. Satu kombinasi terdapat sepuluh ulangan sehingga percobaan dibutuhkan 80 unit pot organik dan semai balsa. 


\section{HASIL DAN PEMBAHASAN}

\section{Pengaruh Interaksi Komposisi Pot Organik dan Penambahan Mikoriza}

Hasil analisis sidik ragam (Tabel 1) menunjukkan bahwa perlakuan interaksi komposisi pot organik dan penambahan FMA berpengaruh nyata terhadap tinggi semai balsa. Tabel 2 menunjukkan perlakuan komposisi pot organik koran:kompos perbandingan 1:1 dengan penambahan FMA menghasilkan respon pertambahan tinggi semai balsa terbaik dibandingkan dengan perlakuan lain. Hal ini sesuai dengan hasil analisis kandungan unsur C-organik, $\mathrm{N}$-total, P-total, P-tersedia dan $\mathrm{C} / \mathrm{N}$ rasio berbagai komposisi pot organik (Tabel 3) yang menunjukkan bahwa komposisi pot organik koran:kompos dengan perbandingan 1:1 mengandung unsur hara $\mathrm{C}$-organik sangat tinggi, $\mathrm{N}$-total tinggi, $\mathrm{P}$-total sangat tinggi, dan P-tersedia sangat tinggi. Menurut Hardjowigeno (2010) kandungan unsur C-Organik tergolong sangat tinggi jika $>5 \%$, kandungan unsur $\mathrm{N}$ tergolong tinggi pada rentang $0.51-0.75 \%$, kandungan $\mathrm{P}-$ total sangat tinggi jika $>60 \mathrm{ppm}$, dan kandungan $\mathrm{P}$ tersedia sangat tinggi jika $>35 \mathrm{ppm}$. Komposisi pot organik koran:kompos dengan perbandingan 1:1 mengandung unsur hara C-organik sebesar $15.76 \%$, kandungan $\mathrm{N}$-total sebesar $0.69 \%$, kandungan P-total sebesar 492.84 ppm, dan kandungan P-tersedia sebesar $150.95 \mathrm{ppm}$.

Hasil analisis kandungan unsur hara C-organik, Ntotal, P-tersedia, P-total, dan $\mathrm{C} / \mathrm{N}$ rasio pada berbagai komposisi pot organik (Tabel 3) menunjukkan bahwa perlakuan komposisi pot organik koran:kompos:arang

Tabel 1 Rekapitulasi hasil analisis sidik ragam pengaruh interaksi komposisi pot organik dan penambahan FMA terhadap parameter pertumbuhan semai balsa

\begin{tabular}{lc}
\hline \multicolumn{1}{c}{ Parameter } & $\begin{array}{c}\text { Hasil analisis sidik } \\
\text { ragam }\end{array}$ \\
\hline Tinggi & $0.01^{*}$ \\
Diameter & $0.13 \mathrm{tn}$ \\
Berat Kering & $0.16 \mathrm{tn}$ \\
$\begin{array}{l}\text { Total (BKT) } \\
\% \text { Kolonisasi } \\
\text { mikoriza }\end{array}$ & $0.55 \mathrm{tn}$ \\
\hline
\end{tabular}

Keterangan:

Angka-angka dalam tabel adalah nilai signifikan.

*= perlakuan berpengaruh nyata pada selang kepercayaan $95 \%$ dengan nilai signifikan $(\operatorname{Pr}>\mathrm{F}) 0.05(\alpha)$

$\mathrm{tn}=$ perlakuan tidak berpengaruh nyata pada selang kepercayaan $95 \%$ dengan nilai signifikan $(\operatorname{Pr}>\mathrm{F}) 0.05(\alpha)$ dengan perbandingan 1:1:1 mempunyai kandungan unsur P-total paling tinggi yaitu sebesar $2351.48 \mathrm{ppm}$. Kandungan unsur P-tersedia paling tinggi terdapat pada perlakuan koran:kompos dengan perbandingan 1:1 yaitu sebesar $150.95 \mathrm{ppm}$. Berdasarkan hasil pengukuran ratarata pertambahan tinggi semai balsa (Tabel 2) menunjukkan bahwa perlakuan yang menghasilkan ratarata pertambahan tinggi paling baik yaitu perlakuan komposisi pot organik koran:kompos perbandingan 1:1 yang diinokulasi dengan mikoriza memiliki rata-rata pertambahan tinggi sebesar $8.17 \mathrm{~cm}$ dibandingkan dengan perlakuan komposisi pot koran:arang dengan perbandingan 1:2 maupun perlakuan komposisi pot organik koran:kompos:arang dengan perbandingan 1:1:1.

Perlakuan komposisi pot organik koran:kompos dengan perbandingan 1:1 mempunyai nilai P-total lebih rendah dibandingkan dengan perlakuan koran:arang perbandingan 1:2 dan perlakuan koran:kompos:arang perbandingan 1:1:1 dengan nilai P-total secara berturutturut sebesar 492.84 ppm, $748.81 \mathrm{ppm}$, dan 2351.48 ppm. Perlakuan koran:kompos memiliki P-tersedia lebih tinggi dibandingkan dengan perlakuan koran:arang dan koran:kompos:arang dengan nilai P-tersedia secara berturut-turut sebesar $150.95 \mathrm{ppm}, 85.70 \mathrm{ppm}$, dan 149.52 ppm. Menurut Budi et al. (2015), kelebihaan unsur $\mathrm{P}$ akan mengurangi kolonisasi dan produksi spora. Nilai P pada komposisi pot organik koran:arang dengan perbandingan 1:2 mempunyai potensi untuk perkembangan FMA karena memiliki nilai P yang lebih rendah. Namun, menurut hasil uji Duncan (Tabel 2)

Tabel 2 Uji Duncan pengaruh interaksi komposisi pot organik dan penambahan FMA terhadap pertambahan tinggi $(\Delta \mathrm{t})$ semai balsa

\begin{tabular}{lcc}
\hline \multicolumn{1}{c}{ Perlakuan } & $\begin{array}{c}\text { Rata- } \\
\text { rata } \Delta \text { t } \\
(\mathrm{cm})\end{array}$ & $\begin{array}{c}\% \\
\text { peningkat- } \\
\text { an }\end{array}$ \\
\hline $\begin{array}{l}\text { Koran100\% (tanpa FMA) } \\
\text { Koran100\% (dengan FMA) }\end{array}$ & $\begin{array}{l}2.33 \mathrm{e} \\
2.87 \mathrm{ed}\end{array}$ & 23.00 \\
$\begin{array}{l}\text { Koran:Kompos=1:1 (tanpa } \\
\text { FMA) }\end{array}$ & $4.23 \mathrm{cb}$ & 81.54 \\
$\begin{array}{l}\text { Koran:Kompos=1:1 (dengan } \\
\text { FMA) }\end{array}$ & $8.17 \mathrm{a}$ & 250.64 \\
$\begin{array}{l}\text { Koran:Arang=1:2 (tanpa } \\
\text { FMA) }\end{array}$ & $3.75 \mathrm{~cd}$ & 60.94 \\
$\begin{array}{l}\text { Koran:Arang=1:2 (dengan } \\
\text { FMA) }\end{array}$ & $4.83 \mathrm{cb}$ & 107.29 \\
$\begin{array}{l}\text { Koran:Kompos:Arang=1:1:1 } \\
\text { (tanpa FMA) }\end{array}$ & $3.89 \mathrm{~cd}$ & 66.95 \\
$\begin{array}{l}\text { Koran:Kompos:Arang=1:1:1 } \\
\text { (dengan FMA) }\end{array}$ & $5.67 \mathrm{~b}$ & 143.35 \\
\hline
\end{tabular}

Keterangan: Angka yang diikuti oleh huruf yang sama menunjukkan perlakuan tidak berbeda nyata pada selang kepercayaan $95 \%$.

Tabel 3 Kandungan unsur C-organik, N-total, P-tersedia, P-total dan C/N rasio berbagai komposisi pot organik

\begin{tabular}{lllllll}
\hline No & \multicolumn{1}{c}{ Perlakuan } & C-Organik (\%) & N-total (\%) & P-tersedia (ppm) & P-total (ppm) & C/N rasio \\
\hline 1 & Koran 100\% & 16.27 & 0.24 & 12.67 & 366.76 & 67.79 \\
2 & Koran:Kompos = 3:2 & 15.76 & 0.69 & 150.95 & 492.84 & 22.84 \\
3 & Koran:Arang = 3:2 & 32.59 & 0.35 & 85.70 & 748.81 & 93.11 \\
4 & Koran:Kompos:Arang = 1:1:1 & 35.41 & 0.52 & 149.52 & 2351.48 & 68.09 \\
\hline
\end{tabular}


menunjukkan pertumbuhan yang kurang baik pada perlakuan komposisi pot organik koran:arang dengan perbandingan 1:2. Menurut Lehmann et al. (2011) menyatakan pemberian arang dapat memberikan efek negatif terhadap kelimpahan FMA yang terjadi akibat menurunnya persyaratan untuk simbiosis FMA. Hal ini menyebabkan pertumbuhan semai pada perlakuan komposisi pot organik koran:arang menjadi kurang baik.

Nilai $\mathrm{C} / \mathrm{N}$ rasio menunjukkan kemudahan suatu bahan untuk terdekomposisi. Menurut Foth (1991) menyatakan ratio $\mathrm{C} / \mathrm{N}$ dari bahan organik dan tanah merupakan petunjuk kemungkinan kekurangan nitrogen dan persaingan di antara mikroba-mikroba dan tanaman tingkat tinggi dalam penggunaan nitrogen yang tersedia dalam tanah. Menurut Hardjowigeno (2010) nilai C/N rasio tergolong tinggi pada rentang 16-25 dan tergolong sangat tinggi pada nilai $>25$. Nilai $\mathrm{C} / \mathrm{N}$ rasio komposisi pot organik koran:kompos dengan perbandingan 1:1 memiliki niai $\mathrm{C} / \mathrm{N}$ rasio yang tinggi, sedangkan perlakuan komposisi pot organik koran:arang dengan perbandingan 1:2, dan koran:kompos:arang dengan perbandingan 1:1:1 memiliki nilai $\mathrm{C} / \mathrm{N}$ rasio yang sangat tinggi. Menurut Hanafiah (2005), apabila nisbah $\mathrm{C} / \mathrm{N}$ lebih kecil dari 20 menunjukkan terjadinya mineralisasi $\mathrm{N}$, apabila lebih besar dari 30 maka terjadi immobilisasi $\mathrm{N}$, jika diantara 20 - 30 berarti mineralisasi seimbang dengan immobilisasi. Menurut Heal et al. (1997), bahan organik akan termineralisasi jika nisbah $\mathrm{C} / \mathrm{N}$ dibawah nilai kritis 25 - 30 dan jika diatas nilai kritis akan terjadi imobilisasi N. Terjadinya immobilisasi hara tanaman dapat menimbulkan gejala defisiensi (Fauzi 2008). Hal ini menunjukkan pada perakuan komposisi pot koran:kompos dengan perbandingan 1:1 dengan penambahan FMA memiliki pertumbuhan paling baik karena mempunyai $\mathrm{C} / \mathrm{N}$ rasio dibawah nilai kritis $25-30$

Tabel 4 Hasil analisis sidik ragam pengaruh komposisi pot organik terhadap pertambahan diameter, \% kolonisasi mikoriza, dan berat kering total

\begin{tabular}{lc}
\hline Parameter & $\begin{array}{c}\text { Hasil analisis } \\
\text { sidik ragam }\end{array}$ \\
\hline Diameter & $<.0001^{*}$ \\
\%Kolonisasi Mikoriza & $0.1086 \mathrm{tn}$ \\
Berat Kering Total & $0.0194^{*}$ \\
\hline
\end{tabular}

\section{Keterangan:}

Angka-angka dalam tabel adalah nilai signifikan. *=perlakuan berpengaruh nyata pada selang kepercayaan $95 \%$ dengan nilai signifikan $(\operatorname{Pr}>\mathrm{F}) 0,05(\alpha)$.

tn=perlakuan tidak berpengaruh nyata pada selang kepercayaan 95\% dengan nilai signifikan $(\mathrm{Pr}>\mathrm{F})$ 0,05 $(\alpha)$ artinya bahan organik dapat termineralisasi sehingga tanaman dapat menyerap unsur hara dengan baik serta nilai $\mathrm{C} / \mathrm{N}$ rasio yang lebih kecil berpotensi sebagai perkembangan FMA jika dibandingkan dengan perlakuan koran:arang perbandingan 1:2 dan perlakuan koran:kompos:arang perbandingan 1:1:1.

\section{Pengaruh Komposisi Pot Organik}

Hasil analisis sidik ragam (Tabel 4) menunjukkan bahwa perlakuan tunggal komposisi pot organik berpengaruh nyata terhadap parameter pertambahan diameter semai balsa. Uji Duncan pengaruh komposisi pot organik terhadap pertambahan diameter semai balsa pada Tabel 5 menunjukkan bahwa perlakuan komposisi pot organik koran:kompos dengan perbandingan 1:1 menghasilkan respon pertambahan diameter terbaik yaitu dengan rata-rata pertambahan diameter $2.13 \mathrm{~cm}$ dan persen peningkatan sebesar $71.77 \%$ dibandingkan dengan kontrol (koran 100\%). Hal ini disebabkan bahan baku kompos mengandung unsur hara yang dibutuhkan oleh tanaman. Kompos dapat meningkatkan pertumbuhan tanaman karena dapat membantu meningkatkan kesuburan tanah dan merangsang pertumbuhan akar (Wasis dan Fathia 2010) dan dapat meningkatkan kandungan bahan organik tanah sehingga mempertahankan dan menambah kesuburan tanah (Simanungkalit et al. 2006).

Arang merupakan suatu padatan berpori yang mengandung 85-95\% karbon, dihasilkan dari bahanbahan yang mengandung karbon dengan pemanasan pada suhu tinggi. arang mampu menyimpan senyawa-senyawa terlarut terutama bahan organik yang terlarut dalam air tanah dapat menjadi habitat baru bagi mikroba tanah yang dapat memiliki kemampuan memanfaatkan senyawa serapan-serapan sebagai sumber energinya (Gunawan 1987). Menurut Suhartana (2006) arang

Tabel 5 Uji Duncan pengaruh komposisi pot organik terhadap pertambahan diameter $(\Delta \mathrm{d})$ semai balsa

\begin{tabular}{lcc}
\hline \multicolumn{1}{c}{ Perlakuan } & $\begin{array}{c}\text { Rata- } \\
\text { rata } \Delta \mathrm{d} \\
(\mathrm{cm})\end{array}$ & $\begin{array}{c}\% \\
\text { Peningkat- } \\
\text { an }\end{array}$ \\
\hline Koran 100\% & $1.24 \mathrm{c}$ & 0.00 \\
Koran:Kompos $=1: 1$ & $2.13 \mathrm{a}$ & 71.77 \\
Koran:Arang = $1: 2$ & $1.71 \mathrm{~b}$ & 37.90 \\
Koran:Kompos:Arang $=$ & $1.98 \mathrm{~b}$ & 59.68 \\
$1: 1: 1$ & & \\
\hline Keran
\end{tabular}

Keterangan: Angka yang diikuti oleh huruf yang sama menunjukkan perlakuan tidak berbedanyata pada selang kepercayaan $95 \%$.

Tabel 6 Uji Duncan pengaruh komposisi pot organik terhadap berat kering total semai balsa

\begin{tabular}{lcc}
\hline \multicolumn{1}{c}{ Perlakuan } & Rata-rata BKT (gram) & \% peningkat-an \\
\hline Koran 100\% & $0.32 \mathrm{~d}$ & 0.00 \\
Koran:Kompos= $1: 1$ & $0.86 \mathrm{a}$ & 166.66 \\
Koran:Arang = $1: 2$ & $0.57 \mathrm{c}$ & 76.85 \\
Koran:Kompos:Arang = 1:1:1 & $0.76 \mathrm{~b}$ & 134.56 \\
\hline
\end{tabular}

Keterangan: Angka yang diikuti oleh huruf yang sama menunjukkan perlakuan tidak berbedanyata pada selang kepercayaan $95 \%$ 
tempurung kelapa merupakan salah satu arang aktif yang mempunyai daya serap atau adsorpsi yang tinggi terhadap larutan atau uap. Arang tempurung kelapa dapat membantu penyerapan unsur hara tetapi ketersediaan unsur haranya lebih rendah dibandingkan dengan kompos sehingga pertumbuhan semai balsa lebih baik pada komposisi pot organik dengan bahan kompos dibandingkan dengan arang tempurung kelapa. Menurut Istantini (2012), arang berfungi sebagai pengatur pada tanah yang ditanami oleh tanaman, arang akan memberikan hara kepada tanaman apabila tanaman mengalami kekurangan hara pada tanah yang miskin hara dan akan mengambil hara apabila di dalam tanah terdapat kandungan hara yang berlebih dan akan memberikan hara yang diambil pada saat tanaman membutuhkannya.

Hasil analisis sidik ragam (Tabel 4) menunjukkan bahwa perlakuan tunggal komposisi pot organik berpengaruh nyata terhadap parameter berat kering total semai balsa. Uji Duncan pengaruh komposisi pot organik terhadap berat kering total semai balsa pada Tabel 6 menunjukkan bahwa perlakuan koran:kompos dengan perbandingan 1:1 mempunyai nilai BKT rata-rata tertinggi yaitu sebesar 0.86 gram dan mengalami persen peningkatan terhadap kontrol sebesar $166.66 \%$. Hal ini disebabkan karena adanya pengaruh komposisi kompos, tanaman mampu menyerap unsur hara yang tersedia didalam media kompos tersebut. Meningkatnya berat kering tanaman berkaitan dengan kondisi pertumbuhan yang lebih baik untuk berlangsungnya aktivitas metabolisme tanaman (Widyani et al. 2003).

Menurut Gardneret al. (1991), adanya peningkatan berat kering suatu tanaman disebabkan oleh peningkatan pengambilan $\mathrm{CO}_{2}$ untuk melakukan fotosintesis. Hasil penelitian Handayani (2009), menunjukkan bahwa perlakuan subsoil yang ditambahkan kompos $20 \%$ mempunyai nilai berat kering yang baik, karena akar tanaman dapat menyerap bahan organik dan unsur hara yang diakomodasikan oleh kompos yang kemudian digunakan dalam proses pertumbuhan, sehingga menghasilkan bibit yang mempunyai pucuk yang lebih lebat dibandingkan dengan bibit yang tumbuh di media subsoil atau subsoil capur kompos 10\%. Dapat

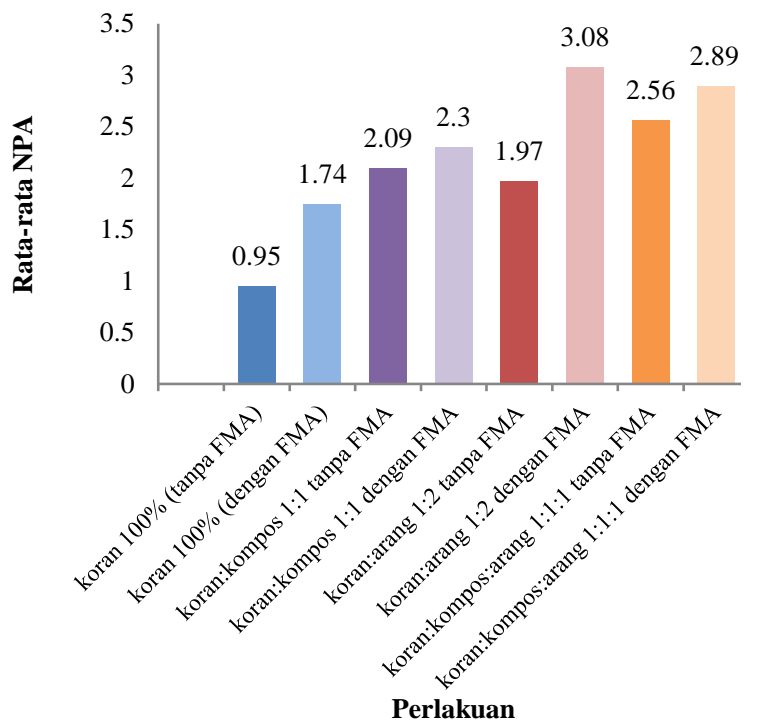

Gambar 1 Diagram nisbah pucuk akar semai balsa disimpulkan semakin tinggi presentasi kompos maka berat kering yang dihasilkan akan semakin tinggi. Hal ini menunjukkan tanaman tersebut mempunyai pertumbuhan secara fisiologis (batang dan daun) yang baik.

\section{Pengaruh Penambahan Mikoriza}

Hasil analisis sidik ragam (Tabel 7) menunjukkan bahwa perlakuan tunggal penambahan FMA berpengaruh nyata terhadap pertambahan diameter, \% kolonisasi FMA, dan berat kering total pada semai balsa.

Perlakuan penambahan FMA menghasilkan respon pertambahan diameter semai (Tabel 8), \% kolonisasi FMA (Tabel 9), dan berat kering total (Tabel 10) yang lebih bagus dibandingkan dengan perlakuan tanpa penambahan FMA. Hal ini menunjukkan bahwa penambahan FMA pada semai balsa membentuk simbiosis yang efektif sehingga menimbulkan respon yang positif tehadap pertumbuhan semai. Hal ini sesuai dengan pernyataan Nusantara et al. (2012) bahwa simbiosis FMA dan akar tanaman dikatakan efektif jika menghasilkan pengaruh yang menguntungkan bagi tanaman inang. Menurut penelitian Budi et al. (2014), bahwa semai $O$. bicolor yang diinokulasi dengan FMA memiliki nilai rata-rata diameter lebih besar daripada perlakuan tanpa FMA.

Menurut Budi et al. (2015) kolonisasi FMA akan menyebabkan perubahan morfologi dan fisiologi akar dan naiknya laju fotosintat dari daun ke akar sehingga terjadi peningkatan pertumbuhan tanaman secara keseluruhan. FMA berfungsi sebagai pompa dan pipa karena dapat membantu tanaman untuk menyerap unsur hara dan air pada lokasi yang tidak terjangkau oleh rambut akar.

Menurut Imas et al. (1989) menyatakan bahwa akar tanaman yang terinfeksi FMA dapat diindikasikan dari adanya vesikula, arbuskula, hifa, dan spora. FMA mempunyai dua macam organ yang terdapat didalam jaringan terinfeksi, yaitu arbuskula dan vesikula. Arbuskula berperan sebagai pemindah unsur hara diantara simbion-simbion, Vesikula terbentuk akibat adaya pembengkakan pada hifa yang berbentuk oval. Fungsi dari vesikula yaitu sebagai organ reproduksi atau organ yang berfungsi sebagai tempat penyimpanan makanan yang kemudian diangkut ke dalam sel (Delvian 2003).

\section{Nisbah Pucuk Akar}

Nisbah pucuk akar adalah perbandingan antara berat kering pucuk dengan berat kering akar. Gambar 1 menunjukkan nilai NPA terendah terdapat pada perlakuan kontrol (koran 100\%) tanpa pemberian FMA (A1B1) dengan nilai NPA sebesar 0.95 dan nilai NPA tertinggi ada pada perlakuan koran:arang perbandingan 1:2 dengan penambahan FMA (A3B2) yaitu sebesar 3.09 .

Menurut Budi et al. (2015), tanaman bermikoriza mempunyai biomassa akar lebih sedikit dibandingkan biomassa pucuk yang berhubungan dengan pengambilan sebagian besar fungsi akar dalam menyerap unsur hara dan air oleh FMA sehingga energi untuk pertumbuhan 
dan perkembangan akar dapat dikurangi, akibatnya nisbah pucuk akar lebih besar pada tanaman yang bermikoriza (Stavros et al. 2012). Hal ini menunjukkan komposisi pot organik dengan penambahan FMA mempunyai nisbah pucuk akar yang lebih tinggi dibandingkan dengan komposisi pot organik yang tidak ada penambahan FMA (Gambar 1).

\section{SIMPULAN DAN SARAN}

\section{Simpulan}

Interaksi komposisi pot organik dan penambahan FMA berpengaruh nyata terhadap tinggi semai balsa $(O$. bicolor Rowlee) dengan perlakuan terbaik yaitu koran:kompos perbandingan 1:1 dengan penambahan FMA. Perlakuan tunggal komposisi pot organik berpengaruh nyata terhadap pertambahan diameter dan berat kering total semai balsa (O. bicolor Rowlee). Perlakuan tunggal penambahan FMA berpengaruh nyata terhadap pertambahan diameter, berat kering total dan \% kolonisasi FMA pada akar semai balsa (O. bicolor Rowlee). Perlakuan komposisi pot organik koran:kompos perbandingan 1:1 dengan penambahan FMA menghasilkan respon pertumbuhan semai balsa $(O$. bicolor Rowlee) terbaik selama 18 minggu pengamatan.

\section{Saran}

Penelitian lebih lanjut mengenai komposisi atau takaran yang sesuai untuk bahan baku pot organik, khususya koran, kompos, dan arang tempurung untuk melihat pengaruh pertumbuhan tanaman. Selain itu, ukuran volume dari pot organik kiranya lebih diperbesar agar media (tanah) bisa masuk lebih banyak dan agar tanaman dapat tumbuh lebih baik.

\section{DAFTAR PUSTAKA}

Budi SW, Saputri TE, Turjaman M. 2014. Pemanfaatan fungi mikoriza arbuskula (FMA) dan arang tempurung kelapa untuk meningkatkan pertumbuhan semai Gmelina arborea Roxb. danOchroma bicolor Rowlee. di persemaian. Jurnal Silvikultur Tropika 5(1):24-32.

Budi SW, Purwanti SI, Turjaman M. 2015. Fungi mikoriza arbuskula dan arang tempurung kelapa mempercepat pertumbuhan awal bibit Calliandra calothyrsus Meissn di media tanah marginal.Jurnal Silvikultur Tropika. 06(2):114118.

Delvian. 2003. Keanekaragaman dan potensi pemanfaatan cendawan mikoriza arbuskula di Hutan pantai[disertasi]. Bogor(ID): IPB.

Fauzi A. 2008. Analisis kadar unsur hara karbon organik dan nitrogen di dalam tanah perkebnan kelapa sawit Bengkalis Riau[Tugas akhir]. Medan(ID): Universitas Sumatera Utara Medan.
Foth HD. 1991. Dasar-dasar Ilmu Tanah. Lampung(ID): Universitas Lampung Press.

Gardner FP, Pearce RB, Mitchell RL. 1991. Fisiologi Tanaman Budidaya. Susilo H, penerjemah. Jakarta(ID):UI Pr. Terjemahan dari: Physiology of Crop Plants.

Gunawan LW. 1987. Teknik Kultur Jaringan. Bogor(ID): Pusat Antar Universitas Bioteknologi IPB.

Hardjowigeno S. 2010. Ilmu Tanah. Jakarta(ID): Akademika Pressindo.

Hanafiah KA. 2005. Dasar-dasar Ilmu Tanah. Jakarta(ID): Raja grafindo persada.

Heal OW, Anderson JM, and Swift MJ. 1997. Plant litter quality and decomposition: An historical overview. In Dirven by Nature Plant Litter Quality and Decomposition, (Eds Cadisch G and Giller $\mathrm{KE}$ ), pp. 3 - 30. Departemen of Biological Sciences. Wey Collage. University of London, UK.

Istiantini A. 2012. Aplikasi arang tempurung kelapa dan kotoran sapi (bokashi) terhadap pertumbuhan semai jabon pada media tanam tailing tambang emas[skripsi]. Bogor(ID): Institut Pertanian Bogor.

Lehmann J, Rillig MC, Thies J, Masiello CA, Hockaday WC, Crowley D. 2011. Biochar effect on soil biota e A review. Elsevier. Journal. Soil Biology \& Biochemistry 43 (2011) 1812-1836.

Nusantara AD, Bertham RYH, Mansur HI. 2012. Bekerja dengan Fungi Mikoriza Arbuskula. Bogor(ID): SEAMEOBIOTROP.

Setiadi Y. 1992. Mengenal Mikoriza, Rhizombium, dan Aktinorizal untu Tanaman Kehutanan. Bogor(ID): Fakultas Kehutanan IPB.

Simanungkalit RDM, Suriadikarta DA, Saraswati R, Setyorini D, Hartatik W. 2006. Pupuk Organik Dan Pupuk Hayati. Bogor(ID): Balai Besar Litbang Sumberdaya Lahan Pertanian Badan Penelitian dan Pengembangan Pertanian.

Stavros DV, George M, Matthias CR. 2012. Do arbuscular mycorrhizal fungi affect the allometric partition of host plant biomass to shoot and roots A meta-analysis of studies from 1990 to 2010. Mycorrhiza (2012) 22:227-235 DOI 10.1007/s0572-011-0398-7.

Suhartana. 2006. Pemanfaatan tempurung kelapa sebagai bahan baku arang aktif dan aplikasinya untuk penjernihan air sumur di Desa Belor Kecamatan Ngaringan Kabupaten Grobogan. Berkala Fisika.9(3):151-156.

Wasis B, Fathia N. 2011. Pertumbuhan semai gmelina dengan berbagai dosis pupuk kompos pada media tanah bekas tambang emas. Jurnal Manajemen Hutan Tropika. 17(1): 29-33.

Widyani N, Setiadi Y, Sudrajat DJ. 2003. Pengaruh inokulasi mikoriza arbuskula dan pemberian pupuk fosfat terhadap pertumbuhan semai Gmelina (Gmelina arborea Roxb.) Buletin Teknologi Perbenihan 10(1): 25-32. 